\title{
Apply MQ Group Discussion to TJPU Tertiary Large Class Teaching in China
}

\author{
Hong Jiang, Hong Zhao \\ College of Economics, Tianjin Polytechnic University, Tianjin \\ 300387, China
}

\begin{abstract}
Focusing on the transferability of effective Group Discussion, the article has compaed the similarities and differences Group Discussion between MQ in Australia and TJPU in China. The aim of this article is mainly to prompt studentcentered course in China. At the end, this article has made some suggestions of how to overcome the challenges and transfer current teaching, learning and communicating methods to the large classes in TJPU in China.

Keywords: group Discussion, critical thinking, large class, transferring approach.
\end{abstract}

\section{Introduction}

A conventional, teacher-centered course might involve the transmission of concepts required for the syllabus, or of knowledge from the lecturer, with few opportunities for interaction and little engagement for absorbing knowledge for student (Daniel J. Exeter, 2010). The disengaged student in teacher-centered class typically only takes notes during the lecture and memorise facts and key points in order to obtain a 'pass' or a 'mark' for the course (Biggs, 1999). Particularly this kind of class pedagogy will only further undermine the capacity of institutions to provide high-quality learning experiences(Catherine Grant, 2013). Students themselves are also disillusioned with out-dated, teacher-centered pedagogies (Catherine Grant, 2013). 
Developing a course curriculum that engages students requires a shift away from the lecture-based course to a more interactive and student-centered mode of teaching (Daniel J. Exeter, 2010). The education environment, especially the tertiary teaching technique should be changed from the teacher-centered to student-centered. There are so many effective and Influential teaching techniques have been used in Australian tertiary teaching, especially, Group discussion has been widely used in most of the class in Macquarie University to help student learn. The most widely accepted explanation of the effective suggests that group discussion facilitates cooperation by offering more opportunity to develop teamwork and improve student engagement (Crisp, 2013).To some extent, it may help to transfer the teacher-centered course to student-centered. This report mainly focuses on the transferability of effective Group Discussion to prompt student-centered course in China. By comparing the similarities and differences Group Discussion between MQ in Australia and TJPU in China, this article will make suggestions for ways to identify and overcome the challenges, transfer current teaching, learning and communicating methods to the tertiary classes in China.

\section{Discussed problems}

The challenges in transferring this approach to China:

Group Discussion is to discuss a topic by a group, which divided by the teacher in the class. Each group conclude individuals with similar interest who gather either formally or informally to bring up ideas, solve problems or give comments. Basically, the goal and the process of it is almost the same in China. To the Teachers, they should carefully define what the group is expected to produce, identify the associated tasks related to the product, and then help students divide tasks and assume individual roles in the group for producing the product (Monica, 2014). But in the concrete implementation procession and effect of this approach, there are still lots of different between these two countries, which could cause many challenges in transferring this approach to China.

\subsection{The basic class scale is different}

In China, most classes are larger than MQ's here, the larger the class scale is, the lower the students' participation is. Because small class can be divided into less number of groups. less groups means more time and more chance for them to present opinions and share ideas. This approach is more likely to improve student 
participation. Degree of student' participation can be improved obviously by less numbers of groups. So in China large class means less degree of participation in the discussion.

\subsection{The time arrangement of Group Discussion and the role of students are different}

In China most of the Group discussion is be arranged extracurricular after the class, but in MQ, the Group Discussion is guided practice by the teachers during the process of class. So practical activities in class can easy help the students get assistance from teachers, gain knowledge actively and develop ability quickly and directly. Secondly, Group Discussion in class is favorable to the teachers themselves, they can listen and grasp information from the students directly, which conclude how they master and where their attention focus on.

\subsection{The purpose of Group Discussion is different to some extent}

The particular aim of Group Discussion in MQ is to cultivate critical thinking ability or to train customized communication habit, which is tend to develop the self-learning and innovative thinking habits. It is clearly that students in active learning environments like these have demonstrated better conceptual grasp of the content as well as better retention rates (Sezer, 2011). In China, we do have the group discussion, but some discussions could not promote the critical thinking effectively, which only be rested on a formalization or simple take the place of the students' homework to get their marks.

\section{Suggestions to overcome some of these challenges in transferring this approach to China}

For Some of the difference may cause the challenges for the teachers in China to transferring this approach to the class, but if we overcome some of them, it is still has high possibility of transferability the effective Group Discuss into the class to improve student's engagement. All the teachers and students, or even the university need to do some changes to realize it.

\subsection{Hardware such as equipments and facilities must be updated.}

From our observation in $\mathrm{MQ}$, removable desks and chairs in the classroom can facilitate group discussion during the lecture at any time, the large area writtenwallboard can push the students to organize and share opinions immediately, also 
the discuss space in the library also facilitate students to share their ideas before or after the class.

\subsection{As teaching skills are improved, teachers should become effective facilitators.}

Basic knowledge could be moved before or after the class by implementing 'flipped approach' in course. During class, teacher should be a learning strategist who constantly plan ways to enable students to master complex content knowledge, guide students in discussion and higher-level problem-based learning activities, develop their critical thinking, problem-solving, communication, and collaboration skills (Hughes, 2012; Monica, 2014).

\subsection{All kinds of new software or website must be learned.}

Teacher must hunt all kinds of new software or website to increase the student' attention and engagement, such as 'padlet' and 'kahoot' or others online learning system. In robust online learning system, students could find all of the class resources for the projects and assignments and can access communication tools through Google Apps for Education, which gives them a suite of free communication and collaboration tools (Monica, 2014). Compared with traditional objectivist (lecture-style) formats, in active online learning environments, students could demonstrate better conceptual grasp of the content as well as better retention rates (Sezer, 2011), as well as increased engagement in learning and improved learning outcomes (Hughes, 2012).

\subsection{The scale of class should not be too large.}

A optimal scale of the class suit to Group Discussion, not too much or too few, are just enough to allow best communication among all decision makers, (i.e., dilemmas restricted to local communities) providing the space and time for the best communication represents themselves (Richard J, Crisp 2013).

\subsection{The strategy of the teacher arrangement should be improved.}

From the teacher topic selection to the student interpretation, the strategy must focus on improving student's engagement. With group Discussion, teacher need to frame the problem and help focus the direction and scaffold it, then associate each other to work through their work. Seeking supplementary information and/or examples beyond those provided in the pre-delivered content, and sharing 
each others; Participating in a performance-based exercise, and making available a broad-written of the process and performance; Creating quizzes, test questions, and other resources to use(Catherine Grant,2013). We should use in-class time for conversations about material that student found confusing or disagreed upon (Haggis, 2006).

\section{Conclusions}

The purpose of Group Discussion be effectively implemented in China was to help student expand the learning, develop critical thinking, and share opinions each other. In breaking with the traditional role of teacher, lecturer should grasp several new models of teaching. They should be strategic in creating opportunities for students to become responsible learners developing their critical thinking, problem-solving, communication, and collaboration skills. They should identify tools and techniques in classes in order to improve students' engagement. Students themselves should also change the study habits from total reception to autonomous learning.

With the tertiary teaching and learning environment changed, new technique available such as Group Discussion gradually implemented in China, as we overcome the challenges, student-centered course can obviously push the students improve their engagement in learning as well as teacher themselves.

\section{Acknowledgements}

The research work was supported by project under Grant No. TJJX13-019 in 2014

\section{References}

[1]Grant, C, First inversion: A rationale for implementing the 'flipped approach' in tertiary music courses, Australian Journal of Music Education, No.1, pp.3-12, 2013.

[2]Exeter, DJ, Student engagement in very large classes: the teachers' perspective, Studies in Higher Education, Vol.35, No.7, pp.761-775, 2010.

[3]Treff, ME, 'Facilitation in Action, The Reflective Practice of Two Facilitators Using a Participation Training Model', ADULT LEARNING, Vol.27, No.3, pp.113-119, 2016.

[4]Crisp, RJ, Simulating Social Dilemmas: Promoting Cooperative Behavior Through Imagined Group Discussion, Journal of Personality and Social Psychology, Vol.104, No.5, pp.839-853, 2013.

[5]Martinez, M, Technology alone won't transform teacher to facilitator, Phi Delta Kappan, Vol.96, pp.41-45. 2014.

[6]Biggs J, What the student does: Teaching for enhanced learning. Higher

Education, Research \& Development, Vol.18, No.1, pp.57-75, 1999. 
[7]Hughes, H, Introduction to flipping the college classroom, Hypermedia and Telecommunications, Vol.9, pp. 2434-2438, 2012.

[8]Haggis T, Pedagogies for diversity: Retaining critical challenge amidst fears of dumbing down, Studies in Higher Education, Vol.31, No.5, pp.521-535, 2006. 